\title{
TEENAGERS AND THE USE OF NEW TECHNOLOGIES (ICT) FOR HEALTH INFORMATION
}

\author{
Alina Duduciuc \\ National University of Political Studies and Public Administration \\ alina.duduciuc@comunicare.ro
}

\begin{abstract}
The spread of health messages through ICTs has raised the issues of source reliability more than ever before. There are many channels for adolescents where they can find information about health, and sometimes these messages are contradictory. In this research I employed a qualitative approach to investigate how adolescents seek information about health through ICTs, what kind of health related topics they search on Internet, whether they rely on their peers, teachers or primary group when they are aware of being in risk, and how they assess a source as trustworthy in covering health information. Additionally, the current study surveys what it means for teenagers to be in a good physical condition, including their habits regarding self-medication, nutrition, physical activity, weight maintenance, and how they communicate with respect to the above-mentioned health-issues through ICTs. On this purpose, I conducted two focus group interviewed with 22 Romanian adolescents, aged between 12 and 17 years, who have Facebook accounts and own smartphones connected to the Internet. The main findings suggest that teenagers search the Internet to some extent as a response to factors that threaten the health condition, such as the presence of physical symptoms that are overwhelming or stressful. The emotional adjustment is rather targeted to social support offline sources (friends, parents and doctors) than online ones.
\end{abstract}

\section{Keywords}

health; ICTs; adolescents; risks; Internet

\section{JEL Classification}

I19

\section{Introduction}

In the last decade, different claims have been embedded in both public as well as academic discourses to explain the dramatic changes of the way teenagers communicate using new technologies (ICT). As they are prone to embrace the ICT rapidly and have highest computer skills, they have been called "digital native" or "early adopters". As we can see from European polls and studies (Eurostat Yearbook 2014; Eurobarometer 2008; Ólafsson, Livingstone \& Haddon, 2013; Mascheroni \& Ólfeson, 2013; Livingstone \& Das, 2010), the period between 2010 and 2014 saw a significant growth of the ICT use among children (9-11 years old) and adolescents (12-16 years old). The percentage of adolescents using laptops (49\%), smartphones (48\%), computers (40\%) and tablets (20\%) rises significantly. Compared with younger children (9-11 years old, 31\%), teenagers (12-17 years old) have been using smartphones (32\%) more than laptops almost since they turned 10 (Mascheroni \& Ólfeson, 2013). When they turn 8, they already know to browse on Internet, and it is prefigured that the age of first Internet use will continue to fall in the next years (Mascheroni \& Ólfeson, 2013). 


\section{Teenagers and the use of ICT for health information: previous studies}

The use of new technology by teenagers for health and disease prevention has been the subject of many recent researches (Jiménez-Pernett et al., 2010, Bailin, Milanaik \& Adesman, 2014; Seçkin, 2014; Fergie, Hunt and Hilton, 2013; Hederson et al., 2013, Landry et al., 2013; Miller \& Bell, 2011; Popa, C., 2013, Wright 2011, Edward, Hart \& Chester, 2010; Kivits, 2009, Tu \& Cohen, 2008, Gray et al., 2005). All these studies have assumed that new technologies - regardless of their symbolic or utilitarian use - are widely present among teenagers. Therefore, the scholars have inquired how these technologies are distributed according young people's health, how and where teenagers are searching for health information, how is health information accessed and used in order to cope with threatening situations and how have the new technologies changed the pattern of communication with doctors and medical staff. Both quantitative research (Jiménez-Pernett et al., 2010; Seçkin, 2014; Hederson et al., 2013, Landry et al., 2013) and qualitative research (Bell, 2014; Fergie, Hunt and Hilton, 2013; Lindqvist 2012, Gray et al., 2005, Skinner et al. 2003; Borzekowski \& Rickert 2001) have shown that young people, in a significant manner, consider the Internet a major source of information on health and disease prevention, especially because it is fast and preserves the anonymity of users. Even if websites and forums are not always assessed by teenagers as reliable sources (Gray et al, 2005), teenagers particularly seek on the Internet information about sex life (Landry et al., 2013; Borzekowski \& Rickert 2001), nutrition, weight maintenance and body image (JiménezPernett et al., 2010, Gray et al., 2005, Skinner et al. 2003), fitness and sports, tattoos and piercings (Jiménez-Pernett et al., 2010).

Recently, a number of studies (Nuutinen et al., 2014; Sinkkonen, Puhakka \& Meriläinen, 2014; Augner \& Hacker, 2012; Punamäki et al., 2007; Koivusilta, Lintonen, \& Rimpelä, 2005) have focused on the effects of ICT proliferation on teenagers' life, questioning the credibility of health information available online. I will review similar articles that have approached this subject.

About ten years ago, when the mobile phone was still spreading among the population of Canadian teenagers, they used the phone to set appointments with friends, rather than to discuss their health problems (Skinner et al. 2003). In the study designed at the University of Toronto, H. Skinner showed that interviewed teenagers $(\mathrm{N}=250)$ believed that the Internet and email were the most accessible technology for information and emotional support. Even they were aware of the credibility and quality of health information retrieved from the websites, they assessed the Internet as the most affordable mean of information because it didn't disclose their identity when they have a problem that could damage the social self, such as sexual or mental health disease. The Internet also helps them to avoid conflicts with parents on issues related to which they have different attitudes. Teenagers also used books to verify the online information as "a book is not published until the information is not checked". The online available information on health is often retrieved from certain websites, and then discussed online or offline with friends. The participants of the research assigned new social roles for healthcare persons as they expected from doctors to recommended, to administrated websites and to go online to ask questions when they doubt about credibility of the websites (Skinner et al., 2003).

A survey based questionnaire (Borzekoweski \& Rickert, 2001) with sample of 412 teenagers from the suburbs of New York indicated that there are gender differences in the perception of credibility of health information retrieved from the Internet. Adolescent girls outnumber boys on disclosing and asking social support from their friends in matter of sex life, nutrition and weight maintenance. They also tend to comply with messages from public health campaigns. The study also showed that American teenagers use the Internet when they want to update their information on contraception and sex life (42\%), fitness (41.6\%), nutrition and weight maintenance 
(36.5\%), alcohol and drugs (24.7\%). They not only use the Internet for the problems mentioned, but consider it as the only reliable, important and valuable source of information on health issues.

Sometimes, the Internet as a source for health information is an occasion for teenagers (11-19 years) to avoid going to the doctor and having a health review (Gray et al., 2005), as shown in a qualitative study conducted in the USA and UK. The Internet is the main source of information for the early teenagers (11-12 years) on topics related to physical and psychological development that occurs during adolescence. Most of them go online to search about nutrition, fitness, diet and claimed to have achieved positive outcomes. However, adolescents often complained about the amount of online health information they had encountered, in this manner the many websites with unspecific information and the pop-ups that promote diet pills or medicines. The authors interpreted the results in the theoretical perspective of the detraditionalization concept, advanced by A. Giddens (1994), taking into account the increase of online support groups, whose members narrate personal experiences with the disease (user generated content) and treatment alternatives which are not always medical.

As far as we have known, no studies have investigated how Romanian teenagers use the Internet for health information seeking. There are several recent studies (Popa, 2014; Comănescu, et al., 2013; Ardeleanu, et al., 2013) that investigated the relation between the use of ICTs, unhealthy behaviours and others specific topic that young people show interest on, in this case alcohol and tobacco consumption, sexual life, nutrition, diets, weight maintenance, fitness. As the previous research revealed, there are many online sources for teenagers where they can find information about health, and sometimes these messages are contradictory. Therefore, the aim of this study is to answer the following questions: a) how teenagers seek information about health through ICTs b) how they engaged in health online content c) whether they rely on their peers, teachers or primary group when they become aware of being at risk and d) how they search for support.

\section{Method}

\section{Participants and sample selection}

To answer the research questions, in June 2014, we conducted two focus groups interviews with adolescents $(\mathrm{N}=22)$ aged between 11 and 17 years old. The first group was composed of seven girls, and the second of girls $(N=8)$ and boys $(N=7)$, all recruited from the suburb area of Bucharest. All group members have known each other and had interacted on previous occasions. This research method was chosen due to several reasons. First, I take into account that one of the key psychological changes that take place in adolescence is the desire to gain independence from parents and to be in tune with the peer group (Brown, 2004). Secondly, I follow up the idea that information retrieved from the Internet and social networking sites is often shared and discussed with others. Therefore, focus group could be a natural setting of gathering data and also a method that can account for social influence processes within social networks.

The selection of subjects was made taking into account several criteria. First of all, whether our subjects own a smartphone connected to the Internet. This criterion was applied due to previous research that showed a recent rise of the use of smartphones among the Romanian children. Here, the number of children who have access to Internet on their phones/smartphones is higher than the EU-average (17\%) (Ólafsson, Living-stone \& Haddon, 2013). Secondly, we consider whether our subjects have a Facebook account and at least one social network profile on YouTube, Instagram, Twitter, and MySpace. And last, whether the overall participants' health was good upon the interview. They only had experienced acute diseases of minor severity and 
had limited experiences with illness, serious or terminal disease. The interviews lasted about an hour and a half and they were recorded. The audio material was transcribed and group into particular themes.

\section{Findings}

\section{ICTs functions and awareness on health issues}

Subjects were invited to join the discussion by commenting on one of the most widespread beliefs within Romanian culture, in this case "Health is wealth". Then, the discussion was orientated toward the use of new technologies. Therefore, subjects were asked how and whether they wish health on their friends' birthdays and what social media technologies they used for this purpose (phone, computer, Internet, email, Facebook). These two "ice breakers" questions have provided some of the research data on subjects' beliefs about health and allowed data collection on the functions of new technologies in the life of teenagers. Most of them expressed that the phone and the SMS can be used when we want to send a personal message; otherwise, when they want to be seen by others form the group, they use Facebook. Being connected to the others through smartphone represents an ongoing experience during the day, as the subjects declared that they access the Internet and Facebook even when they dine. The SMS and Internet connection, particularly to access the Facebook account, are the most common communication functions and technologies among teens. Participants emphasized that they do not think about health because they have only experienced acute pain and have no experience with serious illness. However, during the interview, as they were invited to answer questions, they have thought on health as an important achievement in life, alongside the material and personal ones.

\section{Health information seeking on the Internet and social networking}

The Internet is a "handy" source for teenagers, as it protects them from the costs of not following the social norms, especially when they seek information about their sexual life. Considerably, they use the Internet to learn more about how they could maintain their weight and what physical exercises to do for this. Regarding some minor age-specific issues, such as superficial acne, teenagers interviewed said they sought information on the Internet about this, but they were accidently exposed to friends' posts on Facebook about how to get rid of acne. In this matter, they engaged in the recommended behaviour posted on their Facebook wall. They perceived the Internet as a source that provides wide access to information, but the credibility and usefulness of the information to cope with health problems is being questioned by subjects. As they declared, the Internet and the social media are the space where they have been exposed to their friends "courage" to betake risks behaviours in their struggle to gain autonomy toward parents and teachers.

It seems stupid to read something on the Internet, because you can often get scared. You may not have anything serious, but you read here things and begin to think of something serious. You better go to the doctor than think you're terminally ill [Female, 15 years old].

Wikipedia seems to me as the best site [Male, 16 years old].

Sometimes on Facebook and YouTube I can find ideas about health. I tried the methods posted by friends to get rid of pimples. I tried almost everything, but had no effect [Female, 12 years old]

Often, on their Facebook profile photo, some colleagues show how they exhale smoke......when they exhale smoke...sometimes in colours.....otherwise in patterns....hearts, dragons, etc. Photos are posted after midnight in order for their parents not to see them [Male, 15 years old] 
I searched on the Internet for information about pimples and oily skin reduction. Some treatments on the net helped me but the dermatologist knows best [Female, 15 years old]

Sometimes I read on the Internet and I got scared. I thought I had a serious problem. I still have to go to the doctor to calm myself when I have a problem. I also searched about a friend's health problems .... a friend told me her problem and she was afraid to ask her parents ... I've been looking on the Internet information about her problem....it was actually a sexual problem ....and we got very scared when we read what others were saying on the Internet .... Eventually, she did not avoid the medical investigation, because she was so scared that she had to tell her parents and in the end she went to the doctor... It's good though that when you are looking on the Internet for a shameful word.... nobody on the Internet knows who you are.... [Female, 16 years old]

\section{Nutrition and social context}

Some social contexts, such as gathering with friends, are intake food risk occasions. To gather with friends and have fun with them is to drink soft drinks, eat pizza or eat junk food. Subjects declared that eating healthy means being able to ignore the rules and sometimes to eat fast foods. Even if most of those interviewed said that having a healthy lifestyle consists in eating rationally, having rest, doing regular exercises, avoiding alcohol, tobacco, drugs, some of their nutrition behaviours are however not necessarily related to a good health.

There is not fun in going out without Cola, Sprite, Pepsi, pizza, fast food.... I never saw someone of my age that do not drink and eat like this when going out.... [Male, 17 years old]

\section{Body image, diet and media celebrities}

When I asked what it means for them to have a healthy body, two elements gain more groups approval, in this case doing sports and being thin. Girls voiced more concern than boys with respect to have a face without pimples and a slim body. For them, the weight and the appearance are external indicators of people's health. Only two boys from each focus groups mentioned that having a healthy body means not being sick and not having physical pain. Being asked to describe a person in their family, groups or public space with a healthy body, teenagers indicated mostly sportsmen (especially boys) and media celebrities (mostly girls) from TV series and shows that they usually watch such as actors from The Vampire Diaries, Game of Thrones, How I Met your Mother.

Jennifer Lopez is 40 years old but looks like 20. She exercises a lot and has a strict diet, so she has a healthy body [Female, 15 years old].

A woman with a healthy body has green or blue eyes and is attractive, with build body and muscles. I also like Jan from The Vampire Diaries. He has a healthy body and this is how I would want my husband to look like [Female, 15 years old].

Antonia [a Romanian female music star] has a healthy body because she has undergone plastic surgery and uses all sorts of creams, she always goes to massage sessions and eats what nutritionists tell her [Female, 15 years old].

Lazar Angelor [one of the famous Romanian popular personal trainers] generally looks good because he goes to the gym and eats healthy [Male, 17 years old].

Cristiano Ronaldo has a lot of sport activities and is healthy because he eats healthy [Male, 17 years old].

A person of my age who has a healthy body is a person who looks almost perfect and is tall [Male, 17 years old].

A sociable person who has many friends and goes out often is healthy; she/he does not necessarily have to have brawn [Male, 17 years old]. 
A person of my age who has a healthy body is visibly more beautiful than others. She/he has a perfect skin face and she/he is well-proportioned [Female, 16 years old].

\section{Social support and self-medication}

Subjects were also questioned about the ways in which they get treatment when facing acute headaches. In their answers, no subject indicated the Internet as a source of support for physical pain. Asking parents support or having a rest rather than going online represents ways whereby teenagers carry off the physical discomfort. Some of them mentioned that they take analgesics and anti-inflammatory pills without looking on the leaflet because "this is what my mother gives me and because it makes me feel good." Most of those interviewed know what information a medical prospectus contains, they know that some are contraindicated without medical advice, but this does not have an impact on their behaviour.

\section{Discussion, limits and conclusions}

The data of this study indicated that young people use phone-Internet for search to some extent in order to prevent somatic symptoms and to cope with health problems. They are more interested in the appearance, in problems related to nutrition and weight maintenance to keep up with the ideas of their peers, rather than in issues regarding prevention or health deterioration. Teenagers are exposed to health warning messages accidentally, by change, when accessing certain Internet websites or when connecting to social networks. In this respect, the data of present research is similar to recent findings about adolescents health-seeking behaviours, especially in matters related to sexual diseases, physical exercises, nutrition and weight maintenance (Jiménez-Pernett et al., 2010, Gray et al., 2005, Skinner et al. 2003).

Searching on the Internet of certain medical terms and of health related topics is rather a response to factors that threaten the health condition, such as the presence of physical symptoms that are overwhelming or stressful. Therefore, teenagers develop personal strategies to cope with this threatening situation and use the Internet rather to assess the symptoms. The emotional adjustment effort is rather targeted to social support offline sources such as friends, parents and doctors. I can say, based on these findings, that information on health is retrieved from the Internet and evaluated together with people who have authority and expertise. The results of the present research are similar to previous ones when the health information seeking behaviour was seen as being directed to a purpose or "to achieve cognitive benefits (increasing knowledge levels on a specific disease, information prior to decision, response strategies), behavioural o (increase the ability to take care of yourself), physical benefits (resistance to disease and improving the quality of life) and emotional benefits (reducing anxiety, fear and pain, expectancy)” (Lambert \& Loisel, 2007). The search for information on health includes a wide range of behaviours, such as direct or indirect questions about the matter in question, clarifying questions, disagreements, discussing and exchanging information with other speakers, reading of texts, observation, consultation with a neutral person, browsing and listening (Lambert \& Loisel, 2007).

Even if they have wide access to online information due to the spread of technologies, teenagers question the credibility of sources (Gray et al., 2005) and are sensitive to the risks to which they expose if they do not go to the doctor. In this matter, the data of this research are contrary that previous studies (Nuutinen et al., 2014; Sinkkonen, Puhakka \& Meriläinen, 2014; Augner \& Hacker, 2012; Punamäki et al., 2007; Koivusilta, Lintonen, \& Rimpelä 2005, Palmer et al., 2014; Alexander \& Currie, 2004) that have pointed out that teenagers expose to high risks in the online environment and are passive consumers of online technology and information. We 
can further take into account in which conditions and relations to what do teenagers rather exhibit passivity and engage in behaviours risky to their health. Indeed, the online environment and new communications technologies that they use every day are opportunities to be exposed to risk behaviours considered in tune with the group, as told by the research subjects. Moreover, teenagers betake contrary behaviours to parenting education, such as smoking or alcohol consumption, and post themselves in these situations on social media networks to gain popularity. An active teen on social media networks is also exposed to alternative sources of treatment, often non-medical, in issues related to nutrition or physical appearance, such as methods for treating pimples. Widespread approval of such user-generated content means that teenagers could engage in that behaviour. Teenagers think about health in socio-cultural terms rather than in purely physical ones, as absence of disease or physical symptoms. For them, an adolescent with a good health has a body that approaches images widely accepted in online social networks and promoted in the media (Engeln-Maddox, 2005).

This research was also an occasion of exploring the concept of health information seeking behaviour. Widespread in the health communication and human computer behaviour field, the concept of health information seeking behaviour was operationalized differently and sometimes was used as such without receiving a clarification of terminology or a definition. As mentioned by Sylvie D. Lambert and Carmen G. Loisel (2007), "health seeking behaviour" is a multidimensional concept, referring to individuals' response strategies when there is a threat to their health and also to psychological adjustment strategies when a person copes with a disease. The concept appeared in the vocabulary of engineering, social and behavioural sciences due to the interest of certain researchers and policymakers in understanding how individuals retrieve health information, how they assessed a symptoms in respect with the health online information, what type of messages is preferred (prevention, storytelling, medical) and how they use the information they find. Following the focus group interviews conducted, I think that health information seeking behaviour is a behavioural response that occurs when the individual realizes he/she has a physical symptom. In some research, the concept was generalized also to situations that allow users access to information on health and prevention, considering that the individual is motivated to avoid risks and maximize benefits. The results of the present research indicated that the Internet causes a health information seeking behaviour-response when teenagers are in the stage of assessing the situation and mostly for topics having negative consequences on the self (such as weight, appearance, sexual or mental illnesses). Emotional adjustment is instead provided by parental social support networks probably because they have not been yet complete the process of gaining the autonomy toward parents.

Regarding the teenagers interviewed, I also noted a great awareness of potential risks in relation to self-medication and cases of involuntary or voluntary omission of consulting a medical professional or a leaflet on drugs. However, self-medication is a result of imitating the parental care behaviour. A further study on medication and new technologies could take into account how parents seek information about their children's health and about drugs on the Internet.

In generalizing the conclusions, several limits of the research need to be considered. The participants were quite homogeneous with respect to their age, residence and family income. The focus group could trigger conformity to the others' opinions, as well as reinforcement of stereotypical thinking. Furthermore, the limited number of focus groups conducted for this research does not reflect the diversity of health seeking behaviours through ICTs at adolescence. Therefore, in the next step of the research, larger comparison of data and mixt-methods should be taken into account when analysing health by means of ICTs. 
Despite limitations, there is a very little systematic research on how different age groups access online information on health. As shown by this study, teenagers use Internet to a certain extent and in a given situation: i.e. when they are in danger and when they become aware of a threat to their health, but also when they want to know more information about diseases that could damage their social self (i.e. sexual). They are not passive consumers of online information, but they select and interpret the contents by calling into question the credibility of sources. Parents and health professionals continue to represent for them the persons invested with authority, and this is the reason why they ask their support in the event of physical discomfort. To go out with friends is a social context in which teenagers no longer show sensitivity to risk awareness, by consuming fast food as a symbol of belongingness to a group and by assessing their body in relation to persons considered in vogue and popular by their peers.

\section{Acknowledgements}

This paper was possible with the financial support of the Sectorial Operational Programme for Human Resources Development 2007-2013, co-financed by the European Social Fund, under the project number POSDRU/159/1.5/S/134650 with the title "Doctoral and Postdoctoral Fellowships for young researchers in the fields of Political, Administrative and Communication Sciences and Sociology"

\section{References}

Alexander, L.M., Currie, C. (2004). Young people's computer use: implications for health education, Health Education, 104 (4), 254 - 261.

Ardeleanu, B., Coșoiu, M., Codreanu, M., Nedelcu, E. Rusu, C., Vasilescu., A. (2013). Studiu privind efectul influentei mass-media asupra stării de bine a individului, in Mitrofan, L. Gâtej, E.-R., Coman, F. Studii aplicative în domeniul psihologie sociale (pp. 95-116), București, Editura Sper.

Augner, C., Hacker, G.W. (2012). Associations between problematic mobile phone use and psychological parameters in young adults, International Journal of Public Health, 57 (2), 437-441.

Bailin, A., Milanaik, R., Adesman, A. (2014). Health implications of new age technologies for adolescents: a review of the research, Current Opinion in Pediatrics, 26, 605-619.

Bell, A. (2014). "I Think About Oprah": Social Class Differences in Sources of Health Information, Qualitative Health Research, 24(4), 506-516.

Borzekowski, D.L.G. and Rickert, V.I. (2001). Adolescent cybersurfing for health information: a new resource that crosses barriers, Archives of pediatrics and adolescent medicine, 155 (7), 813-817.

Brown, B. B. (2004). Adolescents' relationships with peers, in Lerner, R. M. and Steinberg, L., Handbook of adolescent psychology (pp. 363-394), New Jersey, John Wiley \& Sons, Inc.

Charlton, A., Bates, C. (2000). Decline in teenage smoking with rise in mobile phone ownership: Hypothesis, British Medical Journal, 321(7269), 1155.

Currie, C., Zanotti, C., Morgan, A., Currie, D., Looze, M., Roberts, C., Samdal, O., Smith, O.R.F., Barnekow, V. (2012). Social determinants of health and well-being among young people. Health behavior in school-aged children (HBSC) study. International report from the 2009/2010 survey (No. 6), Copenhagen: WHO Library Cataloguing in Publication Data, available at URL: 
http://www.euro.who.int/_data/assets/pdf_file/0003/163857/Social-determinantsof-health-and-well-being-among-young-people.pdf

Durkin, K., Barber, B. (2002). Not So Doomed: Computer Game Play and. Positive Adolescent Development, Applied Developmental Psychology, 23, 373-392.

Edwards-Hart, T., Chester, A. (2010). Online mental health resources for adolescents: Overview of research and theory, Australian Psychologist, 45(3), 223-230.

Engeln-Maddox, R. (2005). Cognitive responses to idealized media images of women: The relationship of social comparison and critical processing to body image disturbance in college women, Journal of Social and Clinical Psychology, 24, 1114-1138.

Eurobarometer (2008). Towards a Safer Use of the Internet for Children in the EU: A Parents' Perspective. Luxembourg, available at URL: http://ec.europa.eu/public_opinion/flash/fl_248_en.pdf

Europe in figures - Eurostat yearbook (2014). Information society statistics households and individuals, last update June 2014, available at URL: http://epp.eurostat.ec.europa.eu/statistics_explained/index.php/Eurostat_yearbook.

Fergie, G., Hunt, K.,Hilton, S. (2013).What young people want from health-related online resources: a focus group study, Journal of Youth Studies, 16 (5), 579-596.

Gray, N.J., Klein, J.D., Noyce, P.R., Sesselberg, T.S., Cantrill, J.A. (2005). Health information-seeking behaviour in adolescence: the place of the internet, Social Science \& Medicine 60, 1467-1478.

Hederson, E.M., Keogh, E., Rosser, B.A., Eccleston, Ch. (2012). Searching the internet for help with pain: adolescent search, coping, and medication behaviour, British Journal of Health Psychology, 18, 218-232.

Jiménez-Pernett, J., de Labry-Lima, A.O., Bermúdez-Tamayo, C., García-Gutiérrez, J.F., Salcedo-Sánchez M. del C. (2010). Use of the internet as a source of health information by Spanish adolescents, BMC Medical Informatics and Decision Making, 10 (6), 1-6.

Kautiainen, S., Koivusilta, L., Lintonen, T., Virtanen, S.M., Rimpelä, A. (2005). Use of information and communication technology and prevalence of overweight and obesity among adolescents, International Journal of Obesity, 29 (8), 925-933.

Kivits, J. (2009). Everyday health and the internet: a mediated health perspective on health information seeking, Sociology of Health \& Illness, 31 (5), 673-687.

Koivusilta, L., Lintonen, T., Rimpelä, A.. (2003). Mobile phone use has not replaced smoching in adolescence, British Medical Journal, 326, 161.

Koivusilta, L., Lintonen, T., Rimpelä A. (2005). Intensity of mobile phone use and health compromising behaviours-how is information and communication technology connected to health-related lifestyle in adolescence?, Journal of Adolescence, 28 (1), 35-47.

Koivusilta, L.K., Lintonen, T.P, Rimpelä, A.H. (2007). Orientations in adolescent use of information and communication technology: a digital divide by sociodemographic background, educational career, and health, Scandinavian Journal of Public Health , 35 (1), 95-103.

Kuntsche, Simons-Morton, B., ter Bogt, T., Queija, I.S., Tinoco, V.M. Gaspar de Matos, M., Santinello, M., Lenzi, M. \& the HBSC Peer Culture Focus Group. (2009). Electronic media communication with friends from 2002 to 2006 and links to face-to-face contacts in adolescence: an HBSC study in 31 European and North American countries and regions, International Journal of Public Health, 54(Suppl 2), 243-250.

Lambert, S. D. Loiselle, C. G. (2007). Health information-seeking behavior, Qualitative Health Research, 17(8), 1006-1019. 
Landry, M., Gonzales, F.A, Wood, S., Vyas, A. (2013). New Media Use and Sexual Behavior Among Latino Adolescents, American Journal of Health Behavior, 37 (3) pp. 422-430.

Lindqvist, A.-K., Kostenius C., Gard, G. (2012). "Peers, parents and phones". Swedish adolescents and health promotion, International Journal of Qualitative Studies on Health and Well-being, 7: 17726 - avilable at URL: http://dx.doi.org/10.3402/qhw.v7i0.17726.

Livingstone, S., \& Das, R. (2010). Existential field 8: Media, communication and information technologies in the European family, Working reports: Existential Fields, EF8, Family Platform Project, Avilabale at URL: http://eprints.lse.ac.uk/29788/1/EF8_LSE_MediaFamily_Education.pdf

Mascheroni, G., Ólafsson, K. (2013). Mobile internet access and use among European children, Initial findings of the Net Children Go Mobile project, Milano, Educatt. Available at URL: http://www.netchildrengomobile.eu/reports/

Miller, L.M., Bell, R.B. (2011). Online health information seeeking: the influence of age, information trustworthiness and serach challenges, Journal of Aging and Health, 24 (3), 525-541.

Nuutinen, T., Roos, E., Ray, C., Villberg, J., Välimaa, R., Rasmussen, M., Godeau, E., Beck, F., Léger, D., Tynjäla, J. (2014). Computer use, sleep duration and health symptoms: a cross-sectional study of 15-year olds in three countries, Interantional Journal of Public Health, 59, 619-628.

Ólafsson, K., Livingstone, S., \& Haddon, L. (2013). Children's Use of Online Technologies in Europe. A review of the European evidence base, LSE, London, EU Kids Online.

Palmer, K., Ciccarelli, M., Falkmer, T., Parsons, R. (2014). Associations between exposure to Information and Communication Technology (ICT) and reported discomfort among adolescents, Work , 48, 165-173.

Peretti-Watel, P., Legleye, S., Beck F. (2002). Cigarettes and mobile phones: Are they complementary or substitutable products?, Drugs: Education, Prevention and Policy, 9, 339-343.

Popa, Camelia. (2013). Noi comportamente adictive: Internetul patologic, dependența de SMS-uri și de televizor, București, Editura Universitară.

Punamäki, R.-L., Wallenius, M., Nygård C.-H., Saarni, L., Rimpelä, A.H. (2007). Use of information and communication technology (ICT) and perceived health in adolescence: the role of sleeping habits and waking-time tiredness, Journal of Adolescence, 30 (4), 569-585.

Rocheleau, B. (1995). Computer Use by School-Age Children: Trends, Patterns, and Predictors, Journal of Educational Computing Research, 12(1), 1-17.

Seçkin, G. (2014). Health Information on the Web and Consumers' Perspectives on Health Professionals' Responses to Information Exchange, Medicine 2.0, 3 (2). Available at URL: http://www.medicine20.com/2014/2/e4/

Sinkkonen, H.-M., Puhakka, H., Meriläinen, M. (2014). Internet use and addiction among Finnish Adolescents (15-19 years), Journal of Adolescence, 37, 123-131.

Subrahmanyam, K., Kraunt, R.E., Greenfield, P.M., Gross, E.F. (2000). The Impact of Home Computer Use on Children's Activities and Development, Children and Computer Technology, 10 (2), 123-144.

Skinner, H., Biscope, Poland, B., Goldberg, E. (2003). How adolescents use technology for health information: implications for health professionals from focus group studies, Journal of Medical Internet Research, 5 (4), e32.

Tsitsika, A.K., Tzavela, E.C., Janikian, M., Ólafsson, K., Iordache, A., Schoenmakers, T.M., Tzavara, C., Richardson C. (2014). Online social networking in adolescence: patterns of use in six European countries and links with psychosocial functioning, Journal on Adolescent Health, 55, 141-147. 
Tu, H. T., Cohen, G. R. (2008). Striking Jump in Consumers Seeking Health Care Information, Results from the community tracking study, No. 20, Tracking Report August 2008.

WHO report. (2014). Health for the world's adolescents is a World Health Organization. A second chance in the second decade. Avialable at URL: http://www.who.int/adolescent/second-decade.

Wright, E. (2010). Enter health information technology: expanding theories of the doctor-pacient relationship for the twenty-first century health care delivery system. In Pescosolido, B.A, Martin, J.k., McLeod, J., Rogers, A, Handbook of the Sociologyof Health, Ilness, and Healing. A Blueprint for the 21st Century (pp.345-359), New York: Springer Science \& Bussiness Media. 